\title{
Study of Flow Characteristics Over a Rounded Edge Drop Structure in Open Channel
}

\author{
Shafi Muhammad Kori \\ Department of Civil Engineering, \\ Mehran University of Engineering and \\ Technology, Jamshoro, Pakistan \\ shafi.kori@faculty.muet.edu.pk
}

\author{
Ali Asghar Mahessar \\ Sindh Barrages Improvement Project, \\ Sindh Irrigation Department, \\ Sindh, Pakistan \\ amahessar@yahoo.com
}

\author{
Madeeha Channa \\ USPCAS-W, Mehran University of \\ Engineering and Technology, \\ Jamshoro, Pakistan \\ madehachanna.uspcasw@admin.muet.edu.pk
}

Ashfaque Ahmed Memon

Department of Civil Engineering, Mehran University of Engineering and Technology, Jamshoro, Pakistan ashfaque.memon@faculty.muet.edu.pk

\author{
Abdul Rehman Kori \\ Mehran University of Engineering and Technology, \\ Jamshoro, Pakistan \\ rehmankori57@gmail.com
}

\begin{abstract}
Flow over a drop structure is a form of free overfall called hydraulic drop. Hydraulic drop changes the nature of flow abruptly from sub-critical to super-critical condition. Rapidly varied flow analysis is a complex phenomenon and involves remarkable characteristics. Some of the drop structures constructed in Sindh and Punjab provinces of Pakistan had gone through diverse failures, consequential in interruption of water supply to irrigation fields encountering substantial economic loss. In the present study experiments were carried out in the hydraulic laboratory of Mehran University of Engineering and Technology on round edged drop structure fitted in a horizontal rectangular flume (channel model). Data regarding hydraulic drop and hydraulic jump characteristics were collected during the experiment. The observed data included: flow discharge $(Q)$, radius of rounded edge drop structure $(r)$, height of the structure (h), hydraulic drop length $\left(L_{d}\right)$, hydraulic jump length $\left(L_{j}\right)$, depth of flow at toe of the jump $\left(Y_{1}\right)$ and tailwater depth $\left(Y_{2}\right)$. Applying dimensional analysis, the non-dimensional parameters of the observed data were calculated. Using statistical analysis, empirical relationships among the non-dimensional parameters were established for the appropriate design of the drop structure. The research results showed that the length and depth indices are functions of $D=q^{2} g h^{3}$ and $r / h$ values. It was also found that for rounded-edge drop structure, the length of the stilling basin (LSB) reduces as $r / h$ ratio increases.
\end{abstract}

Keywords-flow characteristics; hydraulic drop; hydraulic jump; length of stilling basin; rectangular channel

\section{INTRODUCTION}

Enormous water resource engineering projects have been built up all over the world. Such man-made interventions, like weirs, barrages, dams, regulators, drops, etc. are key structures for supplying water to agriculture fields and other purposes at safe velocity through conveyance infrastructure. Drop structures take the water flow abruptly from a higher section of the canal to a lower section [1]. Water flowing over a drop structure has tremendous velocity because of its high hydraulic gradient [2]. The structure allows the canal to be constructed as a relatively flat series of sections of different heights. Since the flow passing over the drop structure causes a change in the curvature of the water surface, the flow profile may be broken effectively in a sudden manner. As a result, the formation of the hydraulic jump on downstream apron of the structure due to the free fall after hydraulic drop occurs. Also, water load on downstream apron increases, thereby counteracting the uplift in case of structure laid on permeable foundation.

Authors in [2-7] worked on flow parameters passing over drop structures on horizontal and sloping bed for empirical relationships of horizontal bed channel. Hydraulic engineering systems help in planning and designing the most efficient and economic utilization of water through construction of various storage, diversion, regulation and conveyance structures. The conveyance structures consist of a network of canals with/without fall structure [8-9]. Experimental and analytical research has been carried out on the hydraulic drop and jump in horizontal and sloping bed channel. Hence, empirical relationships of various hydraulic characteristics have been developed [10-12]. Author in [5] derived the set of equations (1)-(4) concerning the hydraulic characteristics due to flow in the horizontal channel passing over square edge drop structure:

$$
\begin{aligned}
& \frac{Y_{1}}{h}=0.54 D^{0.524} \\
& \frac{Y_{2}}{h}=1.66 D^{0.27} \\
& \frac{L_{d}}{h}=4.30 D^{0.27} \\
& \frac{Y_{p}}{h}=1.00 D^{0.22}
\end{aligned}
$$

where, $Y_{1}$ is the initial depth of the flow or depth at toe of the jump, $Y_{2}$ is the sequent depth or tail water depth, $Y_{p}$ is the pool depth, $L_{d}$ is the length of the hydraulic drop, $L_{j}$ is the length of the hydraulic jump, $D \quad\left(=q^{2} / g h^{3}\right)$ is the drop number 
(dimensionless), $h$ is the height of drop structure, $q(=Q / b)$ is the discharge intensity $\left(L^{2} / T\right), Q$ is the flow discharge in the channel $\left(L^{3} / T\right), b$ is the channel width and $g$ is the acceleration due to gravity $\left(L / T^{2}\right)$.

Author in [13] conducted research on the characteristics of flow through a rounded edge drop structure in a rectangular sloping bed channel. He did not take into account the radius of rounded edge of structure, and considered the cumulative bed slope of the channel during the analysis. He developed depth and length indices relationship of hydraulic drop and hydraulic jump with drop number $(D)$ as:

$$
\begin{aligned}
\frac{Y_{1}}{h} & =0.389 D^{0.368} \\
\frac{Y_{2}}{h} & =1.344 D^{0.253} \\
\frac{L_{d}}{h} & =4.30 D^{0.27} \\
\frac{L_{j}}{h} & =6.021 D^{0.257}
\end{aligned}
$$

Authors in [14] extended the work of [5] and developed a series of empirical formulas concerning the hydraulic characteristics of flow over straight drop structure on the cumulative bed slope in the rectangular channel:

$$
\begin{aligned}
\frac{L_{j}}{Y_{1}} & =13.40 D^{-0.17} \\
\frac{L_{j}}{Y_{2}} & =4.30 D^{-0.037} \\
\frac{L_{j}}{h} & =8.50 D^{0.28} \\
\frac{Y_{c}}{L_{c}} & =0.44 D^{0.36} \\
\frac{Y_{p}}{h} & =1.80 D^{0.30} \\
\frac{Y_{1}}{h} & =0.58 D^{0.40} \\
\frac{Y_{2}}{h} & =1.65 D^{0.233} \\
\frac{L_{d}}{h} & =2.00 D^{0.25}
\end{aligned}
$$

where, additionally, $L_{c}$ is the length of critical section of the flow and $Y_{c}\left(=q^{2} / g\right)^{1 / 3}$ is the critical depth.

Authors in [2] worked on the flow characteristics of a round drop structure in a rectangular sloping bed channel and developed empirical formulas for the proper design of drop structures as:

$$
\begin{aligned}
& \frac{Y_{1}}{h}=D^{0.368}(0.403-0.0191 S) \\
& \frac{Y_{2}}{h}=D^{0.253}(1.346+6.389 S) \\
& \frac{L_{d}}{h}=D^{0.244}(2.609+20.623 S) \\
& \frac{L_{j}}{h}=D^{0.17}(3.156+12.56 S) \\
& \frac{L_{j}}{Y_{1}}=D^{-0.198}(8.102+149.594 S)
\end{aligned}
$$

$$
\frac{L_{j}}{Y_{2}}=D^{-0.083}(2.356-3.737 S)
$$

where, additionally, $S$ is bed slope of the channel.

In the present study, the experiments were conducted in a rectangular horizontal bed channel (flume) at the hydraulic laboratory of Mehran University of Engineering and Technology, Jamshoro, Pakistan. Data for basic flow parameters/characteristics of hydraulic drop and hydraulic jump were collected for various flow rates over the rounded edge drop structure. The collected basic flow data were further evaluated through non-dimensional and dimensional analysis using Buckingham $\pi$-theorem. Using non-dimensional parameters, empirical relationships of length and depth indices were developed in terms of $D$ and $r / h$ for appropriate structure design.

\section{APPLICATION OF HYDRAULIC JUMP FORMATION}

In order to design the length of stilling basin (LSB) within the range of hydraulic jump formation downstream of the drop structure, it is essential to calculate the length and depth indices of hydraulic drop and hydraulic jump. There are various practical applications of hydraulic jump formation on downstream apron of the drop structure. Some of them are: to dissipate energy in case of free over falls, barrages, dams, regulators, etc, to decrease flow velocity (super critical to subcritical velocity) in order to avoid the erosion and scouring on downstream side, or to counteract the uplift pressure on the downstream pavement of the hydraulic structure constructed over permeable soil.

\section{EXPERIMENTAL WORK}

Extensive study of free fall over a rounded edge drop structure in a horizontal rectangular channel has been conducted. Different values of $r / h$ and flow rate were used so that a reliable relationship of various flow characteristics of hydraulic drop and hydraulic jump could be developed for the required design parameters.

\section{A. Equipment Setup and Data Collection}

To study the basic characteristics of flow over a rounded edge drop structure, the experiments were conducted in a rectangular tilting flume at the main hydraulic laboratory of Mehran University of Engineering \& Technology. The flume comprises of a glass sided and steel floor working section having breadth, depth and length of $7.6 \mathrm{~cm}, 25 \mathrm{~cm}$ and $600 \mathrm{~cm}$ respectively. It contains water tanks in connection with both $\mathrm{u} / \mathrm{s}$ and $\mathrm{d} / \mathrm{s}$ of the section. An adjustable tail gate was used to control downstream flow depth. Water was discharged through a control valve connected to the centrifugal pump and the discharge was measured with a discharge gauge-meter connected by the pump. Water depth data were measured with a sliding pointer gauge attached to the working section of the waterway. Sixteen values for each hydraulic parameter were totally collected using four different heights of the droplet structure with the same rounded radius of $5 \mathrm{~cm}$. Flow geometry and flow characteristics of the structure are shown in Figure 1. 


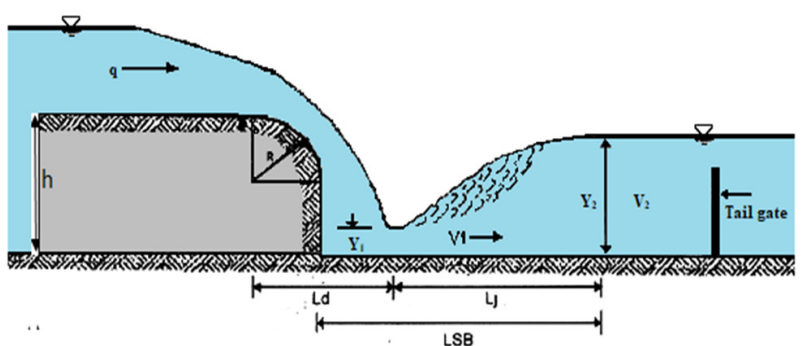

Fig. 1. Flow characteristics during the formation of hydraulic jump, as a result of hydraulic drop

\section{RESULTS AND DISCUSSION}

The hydraulic data collected regarding flow parameters (passing through rounded edge drop structure) during experimentation in the laboratory and computed nondimensional parameters are represented in Table I. By statistical analysis, using multiple regression, the respective relationships of $Y_{1} / h, Y_{2} / h, L_{d} / h, L_{j} / h, L S B / h$ and $Y_{1} / Y_{2}$ in terms of $D\left(=q^{2} / g h^{3}\right)$ and $r / h$ were obtained. The developed equations with correlation coefficient $\left(R^{2}\right)$ are expressed in (23)-(28):

$$
\begin{aligned}
& \frac{Y_{1}}{h}=0.710 D+0.151 \frac{r}{h}+0.067\left(\mathrm{R}^{2}=0.973\right) \\
& \frac{Y_{2}}{h}=0.395 D+1.070 \frac{r}{h}+0.243\left(\mathrm{R}^{2}=0.949\right) \\
& \frac{L_{d}}{h}=0.741 D+2.423 \frac{r}{h}+0.105\left(\mathrm{R}^{2}=0.928\right) \\
& \frac{L_{j}}{h}=8.615 D+0.307 \frac{r}{h}+4.455\left(\mathrm{R}^{2}=0.752\right) \\
& \frac{L S B}{h}=9.357 D+1.370 \frac{r}{h}+4.560\left(\mathrm{R}^{2}=0.786\right) \\
& \frac{Y_{1}}{Y_{2}}=0.401 D-0.013 \frac{r}{h}+0.2071 \quad\left(\mathrm{R}^{2}=0.946\right)
\end{aligned}
$$

\begin{tabular}{|c|c|c|c|c|c|c|c|c|c|c|c|c|c|c|c|c|}
\hline $\begin{array}{c}\text { S. } \\
\text { No. }\end{array}$ & $\begin{array}{c}h \\
(\mathrm{~cm})\end{array}$ & $\begin{array}{c}\frac{Q}{\left(\mathrm{~cm}^{3} / \mathrm{sec}\right)} \\
.\end{array}$ & $\begin{array}{c}q=Q / b \\
\left(\mathrm{~cm}^{2} / \mathrm{sec}\right)\end{array}$ & $\begin{array}{c}Y_{1} \\
(\mathbf{c m})\end{array}$ & $\begin{array}{c}Y_{2} \\
(\mathrm{~cm})\end{array}$ &  & $\begin{array}{c}L_{j} \\
(\mathbf{c m})\end{array}$ & $\begin{array}{l}L S B \\
(\mathrm{~cm})\end{array}$ & $r / h$ & $D=q^{2} / g h^{3}$ & $\boldsymbol{Y}_{1} / \boldsymbol{h}$ & $\boldsymbol{Y}_{2} / \boldsymbol{h}$ & $L_{d} / h$ & $L_{j} / h$ & $L S B / h$ & $\boldsymbol{Y}_{1} / \boldsymbol{Y}_{2}$ \\
\hline 1 & 2 & 3 & 4 & 5 & 6 & 7 & 8 & 9 & 10 & 11 & 12 & 13 & 14 & 15 & 16 & 17 \\
\hline 1 & 13 & 1675.54 & 220.47 & 1.85 & 8.70 & 13.1 & 65.0 & 73.1 & 0.38 & 0.02 & 0.14 & 0.67 & 1.01 & 5.00 & 5.62 & 0.21 \\
\hline 2 & 13 & 1654.82 & 217.74 & 1.85 & 8.50 & 12.8 & 57.3 & 65.1 & 0.38 & 0.02 & 0.14 & 0.65 & 0.99 & 4.41 & 5.01 & 0.22 \\
\hline 3 & 13 & 1520.00 & 200.00 & 1.65 & 8.20 & 12.5 & 57.0 & 64.5 & 0.38 & 0.02 & 0.13 & 0.63 & 0.96 & 4.39 & 4.96 & 0.20 \\
\hline 4 & 13 & 1435.16 & 188.84 & 1.50 & 7.30 & 12.0 & 52.0 & 59.0 & 0.38 & 0.02 & 0.12 & 0.56 & 0.92 & 4.00 & 4.54 & 0.21 \\
\hline 5 & 8.9 & 1675.54 & 220.47 & 2.00 & 8.90 & 15.0 & 53.5 & 63.5 & 0.56 & 0.07 & 0.23 & 1.00 & 1.69 & 6.01 & 7.14 & 0.23 \\
\hline 6 & 8.9 & 1654.82 & 217.74 & 1.90 & 8.20 & 14.5 & 50.0 & 59.5 & 0.56 & 0.07 & 0.21 & 0.92 & 1.63 & 5.62 & 99 & 0.23 \\
\hline 7 & 8.9 & 1520.00 & 200.00 & 1.80 & 8.00 & 13.5 & 48.5 & 57.0 & 0.56 & 0.06 & 0.20 & 0.90 & 1.52 & 5.45 & 6.40 & 0.23 \\
\hline 8 & 8.9 & 1435.16 & 188.84 & 1.60 & 7.60 & 13.0 & 46.0 & 54.0 & 0.56 & 0.05 & 0.18 & 0.85 & 1.46 & 5.17 & 6.07 & 0.21 \\
\hline 9 & 7.3 & 1675.53 & 220.47 & 2.10 & 7.90 & 15.0 & 45.0 & 55.0 & 0.68 & 0.13 & 0.29 & 1.08 & 2.06 & 6.16 & 7.53 & 0.27 \\
\hline 10 & 7.3 & 1654.82 & 217.74 & 1.90 & 7.60 & 14.5 & 43.5 & 53.0 & 0.68 & 0.12 & 0.26 & 1.04 & 1.99 & 5.96 & 7.26 & 0.25 \\
\hline 11 & 7.3 & 1520.00 & 200.00 & 1.80 & 7.30 & 14.0 & 42.0 & 51.0 & 0.68 & 0.11 & 0.25 & 1.00 & 1.92 & 5.75 & 6.99 & 0.25 \\
\hline 12 & 7.3 & 1435.16 & 188.84 & 1.60 & 7.10 & 13.7 & 37.0 & 45.7 & 0.68 & 0.09 & 0.22 & 0.97 & 1.88 & 5.07 & 6.26 & 0.23 \\
\hline 13 & 5.7 & 1675.53 & 220.47 & 2.30 & 7.50 & 14.8 & 42.7 & 52.5 & 0.88 & 0.27 & 0.40 & 1.32 & 2.60 & 7.49 & 9.21 & 0.31 \\
\hline 14 & 5.7 & 1654.82 & 217.74 & 2.10 & 7.30 & 13.6 & 39.0 & 47.6 & 0.88 & 0.26 & 0.37 & 1.28 & 2.39 & 6.84 & 8.35 & 0.29 \\
\hline 15 & 5.7 & 1520.00 & 200.00 & 2.00 & 7.00 & 12.8 & 35.7 & 43.5 & 0.88 & 0.22 & 0.35 & 1.23 & 2.25 & 6.26 & 7.63 & 0.29 \\
\hline 16 & 5.7 & 1435.16 & 188.84 & 1.85 & 6.80 & 11.6 & 32.0 & 38.6 & 0.88 & 0.20 & 0.33 & 1.19 & 2.04 & 5.61 & 6.77 & 0.27 \\
\hline
\end{tabular}

\begin{tabular}{|c|c|c|c|c|c|c|c|c|c|c|c|c|c|c|c|c|c|}
\hline \multirow{2}{*}{$\begin{array}{c}\text { S. } \\
\text { No. }\end{array}$} & \multicolumn{5}{|c|}{$Y_{1}$} & \multicolumn{3}{|c|}{$Y_{2}$} & \multicolumn{3}{|c|}{$L_{d}$} & \multicolumn{3}{|c|}{$L_{j}$} & \multicolumn{3}{|c|}{$L S B$} \\
\hline & Obs & (23) & APE & (28) & APE & Obs & (24) & APE & Obs & (25) & APE & Obs & (26) & APE & Obs & (27) & APE \\
\hline 1 & 1.85 & 1.84 & 0.76 & 1.84 & 0.78 & 8.7 & 8.62 & 0.87 & 13.1 & 13.70 & 4.55 & 65 & 61.97 & 4.65 & 73.1 & 70.7 & 3.3 \\
\hline 2 & 1.85 & 1.83 & 1.04 & 1.79 & 3.16 & 8.5 & 8.62 & 1.43 & 12.8 & 13.69 & 6.96 & 57.3 & 61.91 & 8.05 & 65.1 & 70.6 & 8.4 \\
\hline 3 & 1.65 & 1.80 & 9.03 & 1.72 & 4.06 & 8.2 & 8.60 & 4.92 & 12.5 & 13.66 & 9.26 & 57 & 61.53 & 7.94 & 64.5 & 70.2 & 8.8 \\
\hline 4 & 1.5 & 1.78 & 18.70 & 1.52 & 1.51 & 7.3 & 8.59 & 17.72 & 12 & 13.64 & 13.65 & 52 & 61.30 & 17.89 & 59 & 69.9 & 18.5 \\
\hline 5 & 2 & 1.80 & 10.13 & 2.03 & 1.34 & 8.9 & 7.76 & 12.82 & 15 & 13.51 & 9.92 & 53.5 & 46.57 & 12.95 & 63.5 & 55.1 & 13.3 \\
\hline 6 & 1.9 & 1.79 & 5.98 & 1.86 & 2.01 & 8.2 & 7.75 & 5.45 & 14.5 & 13.50 & 6.89 & 50 & 46.44 & 7.12 & 59.5 & 54.9 & 7.7 \\
\hline 7 & 1.8 & 1.72 & 4.52 & 1.78 & 1.00 & 8 & 7.72 & 3.56 & 13.5 & 13.43 & 0.52 & 48.5 & 45.62 & 5.94 & 57 & 54.0 & 5.2 \\
\hline 8 & 1.6 & 1.68 & 4.93 & 1.67 & 4.61 & 7.6 & 7.69 & 1.22 & 13 & 13.39 & 2.99 & 46 & 45.14 & 1.88 & 54 & 53.5 & 0.9 \\
\hline 9 & 2.1 & 1.91 & 9.23 & 1.97 & 6.35 & 7.9 & 7.49 & 5.19 & 15 & 13.57 & 9.53 & 45 & 42.07 & 6.52 & 55 & 50.6 & 7.9 \\
\hline 10 & 1.9 & 1.89 & 0.53 & 1.88 & 0.92 & 7.6 & 7.48 & 1.56 & 14.5 & 13.55 & 6.53 & 43.5 & 41.87 & 3.75 & 53 & 50.4 & 4.9 \\
\hline 11 & 1.8 & 1.79 & 0.59 & 1.75 & 2.70 & 7.3 & 7.43 & 1.71 & 14 & 13.45 & 3.94 & 42 & 40.65 & 3.22 & 51 & 49.1 & 3.7 \\
\hline 12 & 1.6 & 1.73 & 8.15 & 1.67 & 4.44 & 7.1 & 7.39 & 4.12 & 13.7 & 13.39 & 2.29 & 37 & 39.93 & 7.92 & 45.7 & 48.3 & 5.7 \\
\hline 13 & 2.3 & 2.22 & 3.40 & 2.27 & 1.35 & 7.5 & 7.34 & 2.18 & 14.8 & 13.84 & 6.46 & 42.7 & 40.07 & 6.17 & 52.5 & 48.9 & 6.8 \\
\hline 14 & 2.1 & 2.20 & 4.54 & 2.19 & 4.25 & 7.3 & 7.32 & 0.29 & 13.6 & 13.82 & 1.59 & 39 & 39.74 & 1.90 & 47.6 & 48.6 & 2.0 \\
\hline 15 & 2 & 2.03 & 1.50 & 1.98 & 0.76 & 7 & 7.23 & 3.28 & 12.8 & 13.64 & 6.59 & 35.7 & 37.74 & 5.71 & 43.5 & 46.4 & 6.6 \\
\hline 16 & 1.85 & 1.93 & 4.51 & 1.86 & 0.71 & 6.8 & 7.18 & 5.53 & 11.6 & 13.54 & 16.74 & 32 & 36.57 & 14.27 & 38.6 & 45.1 & 16.9 \\
\hline \multicolumn{3}{|c|}{ MAPE } & 5.47 & & 2.50 & & & 4.49 & & & 6.78 & & & 7.24 & & & 7.54 \\
\hline
\end{tabular}

TABLE I. COLLECTED EXPERIMENTAL DATA FOR FLOW PARAMETERS AND CORRESPONDING NON-DIMENSIONAL PARAMETERS

bed width $b=7.6$, radius of rounded edge $r=5 \mathrm{~cm}$

TABLE II. OBSERVED DATA VS CALCULATED VALUES IN TERMS OF MAPE FOR HYDRAULIC DROP AND JUMP CHARACTERISTICS 
In order to check the accuracy of the developed equations, measures of the goodness of fit were used for comparison between observed and calculated parameters. The mean absolute percentage error (MAPE) was calculated using the following equation:

$$
\text { MAPE }=\frac{100 \%}{n} \sum_{i=1}^{n}\left|\frac{\left(o_{i}-C_{i}\right)}{o_{i}}\right|
$$

where $O_{i}$ is the actual/observed value and $C_{i}$ is the predicted/calculated value. The computed results of MAPE are shown in Table II, which varies between 2.50 and $7.54 \%$ (i.e. less than 10\%). A good agreement between calculated and observed values is obtained, which verifies the developed models/equations.

\section{CONCLUSIONS}

The following conclusions can be drawn from the present study:

- The developed equations (23)-(28) show that the length and depth indices are functions of $D=q^{2} / g h^{3}$ and $r / h$.

- It was also found that if the ratio $r / h$ of rounded-edge drop structure will increase, the length of stilling basin (LSB) reduces.

\section{ACKNOWLEDGMENT}

The authors are thankful to the Institute of Water Resources Engineering and Management, Mehran University of Engineering \& Technology, Jamshoro, Pakistan for providing the facilities to conduct laboratory experiments.

\section{REFERENCES}

[1] FAO, Corporate Document Repository, Irrigation Water Management: Introduction to Irrigation, Produced by Natural Resources Management and Environmental Department, Ashgate Publishing, 1979

[2] S. M. Kori, N. A. Memon, M. T. Shaikh, "Flow Characteristics of Round-Edged Drop Structure in Rectangular Sloping Bed Channel", Pakistan Journal of Agriculture, Agricultural Engineering and Veterinary Sciences, Vol. 24, No. 1, pp. 68-73, 2008

[3] H. B. Bhutto, Hydraulic Jump Control and Energy Dissipation, $\mathrm{PhD}$ Thesis, Mehran University of Engineering and Technology, 1987

[4] M. Y. Shoro, Hydraulic Jump as an Energy Dissipater, MSc Thesis, Mehran University of Engineering and Technology, 1991

[5] W. Rand, "Flow Geometry at Straight Drop Spillways", in: Proceedings of the American Society of Civil Engineers, Vol. 81, No. 9, pp. 1-13, ASCE, 1955

[6] A. H. Shaikh, S. M. Kori, A. L. Qureshi, "Characteristics of Flow for Different Shapes of Drop Structure in Rectangular Horizontal Chanel", Pakistan Journal of Agriculture, Agricultural Engineering and Veterinary Sciences, Vol. 23, No. 2, pp. 35-43, 2007

[7] A. H. Shaikh, S. M. Kori, A. L. Qureshi, "Analysis of Hydraulic Jump Formed Below a Straight Drop in Horizontal Rectangular Channel", Mehran Universcity Research Journal of Engineering and Technology, Vol. 27, No. 2, pp. 153-156, 2008

[8] B. S. Thandaveswara, "Hydraulics Course Material", Section 29.5, 2017, acceced January 8, 2017 from nptel.ac.in/courses/105106114/pdfs/ Unit29/29_5.pdf

[9] K. Safranez, "Researches relating to the hydraulic jump. Basinginieur", (English translation by D. P. Barnes), No. 27, 38, Bureau of Reclamation Files, Denver, Colarado, USA, 1934

[10] S. M. Kori, M. T. Shaikh, A. L. Qureshi, "Flow Over Sharped Edge Drops Structures in Rectangular Sloping Bed Chanel", Mehran
Universcity Research Journal of Engineering and Technology, Vol. 18, No. 3, pp. 167-176, 1999

[11] B. A. Bakhmateff, A. E. Matzke, "The Hydraulic Jump in Terms of Dynamic Similarity", Transactions of the American Society of Civil Engineers, Vol. 101, No. 1, pp. 630-647, 1936

[12] H. Rouse, S. M. Woodward, R. E. Kennedy, L. S. Hall, M. P. O’Brien, F. V. A. E. Engel, B. M. Woods, J. C. Stevens, N. Page, A. I. Ivanchenko, F. T. Mavis, A. Luksch, I. M. Nelidov, "Discussion of 'The Hydraulic Jump In Terms Dynamic Similarity by Boris A. Bakhmeteff and Arthur E. Matzke' ", Transactions of the American Society of Civil Engineers, Vol. 101, No. 1, pp. 648-672, 1936

[13] M. T. Shaikh, Laboratory Study on Basic Characteristics of Hydraulic Drop Structures, MSc Thesis, Mehran University of Engineering and Technology, 1996

[14] S. M. Kori, M. A. Shaikh, A. M. Phul, "Hydraulic Characteristics of Straight Drop Structures", Mehran University Research Journal of Engineering and Technology, Vol. 16, No. 1, pp. 33-39, 1997 